\title{
Conceptualizing and Designing a Resilience Information Portal
}

\author{
Tim A. Majchrzak, Mihoko Sakurai \\ University of Agder, Kristiansand, Norway \\ Email:\{timam,mihoko.sakurai\}@uia.no
}

\author{
Nicolas Serrano \\ University of Navarra, TECNUN \\ School of Engineering, San Sebastian, Spain \\ Email: nserrano@tecnun.es
}

\begin{abstract}
Cities need to cater for the challenges they face. They must endure, respond to, and adapt to short-term shocks and long-term stresses. This ability is now commonly referred to as resilience. Communication and collaboration are vital aspects of a city's effort of becoming (more) resilient. In particular, cities ought to engage their citizens, who ultimately are those that make it resilient - and who benefit from their city's resilience. In this paper we present work from a largescale research project with a considerably practical focus. We have employed IT artefacts to conceptualize and design what we call a Resilience Information Portal. This portal is meant to be the unifier of communication and collaboration efforts of a city. Our proposal takes into account that the basic technological artefacts already exist and are relatively simple, but that the actual problem is complex and requires the integration of various IT systems.
\end{abstract}

\section{Introduction}

Cities today face many challenges. Typically, these are summarized as shocks and stresses [1]. Shocks are shortterm or even immediate problems and that typically have very direct consequences on a city [1]. This comprises of natural disasters such as earthquakes and flooding, and also of events such as acts of terrorism. Stresses do not strike immediately but have a long-term (possibly) negative effect on a city [1]. Typical examples are demographic change and large-scale migrations. Some challenges can pose both characteristics of shocks and stresses. For example, a pandemic typically put stress on a city unless that city faces a severe outbreak of the disease - it then must react to a shock.

Shocks and stresses alike put strains on a city. If not handled successfully, the life of citizens will be burdened or even endangered [1]. Therefore, cities ought to become (more) resilient [2]. Resilience describes the ability of a system to withstand events that may disrupt it [3]. This is possible in several ways. By being prepared a city might be little affected by an event. If it is affected, it should recover, ideally reaching a state at least as good as the state before. Finally, a city should adapt to be better prepared for future events. While this basic setting is simple in explanation, the ramifications are bold due to the underlying complexity of the processes and structures.

We explore the above sketched problem in a large-scale research project. Due to its composition, this project has a very practical flavour: The consortium does not only consist of four academic institutions but also of a city consulting NGO, a standardization organisation, and - particularly notable - seven cities. The project seeks to provide guidelines and tools that help cities in becoming more resilience. A core idea is fo facilitate communication and collaboration between cities, which can form a resilience backbone.

In this paper we present work on one of the main tools of the project, namely the Resilience Information portal. It is a technological artefact, more specifically a Web-based information system (IS). It embodies the idea that a city alone - in the sense of the city council and resiliencerelated units - cannot successfully build a high level of resilience. Rather, it needs to communicate with its citizens and collaborate with key stakeholders. The engagement of citizens can be supported if not even facilitated through an IS. Data exchange and most communication activities with stakeholders nowadays are digital anyway, but typically greatly fragmented. Therefore, our portal is supposed to channel communication, collaboration and eventually engagement to empower citizens, and to coordinate with stakeholders.

The creation of Web-based portals is well understood [4]; The underlying technology is mature (cf. e.g. [5], [6]). However, creating a portal that is really useful to cities and will be used in the long-term is no straightforward task. Therefore, we have chosen a careful approach that especially focusses on close, intensive and continuous work with our partner cities. Based on the insights from this process and in consideration of the literature, we set out to conceptualize the portal. In further consultancy with the cities we moved from requirements to the design of the portal.

Our paper makes several contributions. First, we describe requirement for a information system to support municipal resilience with a particular focus on communication and collaboration. Second, we illustrate the design of such a portal. Thirdly, we generalize our results and provide advise as well as a research agenda.

The remainder is structured as follows. Section 2 explains the background of our work. Although we followed an agile development method and worked incrementally, iteratively, 
and evolutionary, for the purpose of sequential presentation the main parts in Section 3 and Section 4 follow the typical, waterfall-like scheme [7], [8] of analysis, design, implementation, and testing. We then discuss our work in Section 5 before drawing a conclusion in Section 6 .

\section{Background}

In the following, we explain the background of our work. We describe the context of the underlying project, illustrate our research method, and finally discuss related work.

\subsection{About the Project}

The project started in 2015. The overall objective is to enhance urban resilience to tackle short-term shocks and long-term stresses. The characteristic of the project is to take a holistic approach towards resilience. We first worked on three different categories of resilience, which are critical infrastructure, climate change, and social issues, to collect cities' challenges and practice respectively.

54 per cent of the world's population lives in urban areas [9]. The total number of people living in predominantly urban regions in Europe rising by 24.1 million persons by 2050 [10]. Cities are responsible for critical infrastructure management, emergency management and social issue management. In this sense, Europe's resilience must emerge from cities and their networks. After the project period, the partner cities ought to become a part of Europe's resilience backbone, distributing outcomes of the project to other cities.

The project aims at developing a European Resilience Management Guideline until May 2018. The guideline is developed with a set of tools; Each tool will answer how to achieve high-level resilience maturity in different ways (cf. [11]). The first tool is a maturity model, which is used for assessing the maturity level of resilience. The model contains five stages - Start, Moderate, Advance, Robust and Vertebrate - and four dimensions - Leadership \& Governance, Preparedness, Infrastructure \& Resource, and Cooperation. It shows the ideal path towards resilience in each dimension. The second tool is resilience policies. They help a city to enhance resilience in the four dimensions. The third one is a risk systemicity questionnaire, supporting selfassessment of city's vulnerabilities. The fourth tool works in combination with the maturity model. It is named the system dynamics model and enables cities to simulate achievements toward resilience. The final tool is the Resilience Information Portal (cf. also [12]), which is the main topic of this paper. It was designed during the first 18 months of the project, to be available as a resource afterwards. The portal provides an environment for communication and collaboration between cities and stakeholder as well as citizen. It should facilitate urban resilience with technological means. The portal is developed as a toolbox and shows desired functionality for

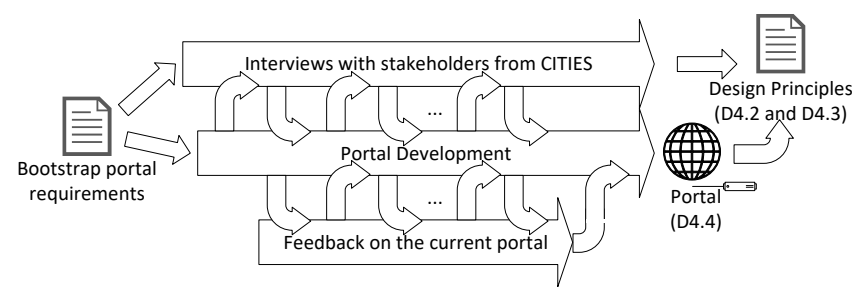

Figure 1. Scheme of the development process (cf. [13])

enabling and improving communication, sharing information and knowledge, building a collective learning loop, and integrating information and services. Cities can use this functionality to design their own portal based on their needs.

\subsection{Research Method}

Our work mandated a carefully tailored research design. First, it needed to cater for providing results not only relevant but producible in practice. This practical relevance is important even beyond the project. At the same time, it ought to be rigorous and thereby allow for scientific contributions. Second, the method needed to be capable of initiating the research process with little prior knowledge but to rapidly come to first results. Thirdly, we had to combine qualitative, design-oriented, and experimental research, i.e. chose a research design that is sound from the perspectives of computer science and of the social sciences.

A high-level view of our research process is depicted in Figure 1. In general, we faced a kind of hen-egg problem: discussing an information system for communication, collaboration and engagement without any such system in place is very hard. A high level of abstraction and a lack of practical experience impede the creation of a vision of requirements. However, providing a portal as a foundation of discussion is not possible without priorly having done work on the requirements. The work through an 18 months period can be sketched as follows (cf. with Figure 1):

- We started with a literature study to find out about existing approaches in science and practice.

- To initiate the process, we bootstrapped requirements to conceptualize an initial portal. This initial set was based on generally acknowledged practices in Web development, specifically portals. We enriched the requirements with the insights from the literature study as well as with prior experiences we had in this field.

- With the initial concept we went into interviews with cities. In particular, we spoke to city stakeholders to learn about their experiences and expectations.

- We kept discussing requirements for a time before moving on to design and eventually implementation. Moving on did not make requirements static, though.

- We gained feedback on the current status on the portal, both from former interview partners and from additional stakeholders, such as the other project partners. 
Conducting our research in this way led to two working products: design principles and a functional specification. The latter serves as a working documents, following a typical form proposed by the software engineering literature (cf. [14][15, Cha. 20.3]) and acknowledged by standards such as IEEE 29148-2011 ${ }^{1}$. It reflects the results from the development process, becoming more stable and coherent over time. The design principles were derived by first identifying communication challenges. Understanding how these challenges should be tackled in cities, we derived design goals. Further generalization led to the principles.

The research process aligns with an agile development process (cf. [16]). We chose an agile procedure to cater for the developing set of requirements. Requirements could not be considered stable or even static, as we (and also the cities) learned about the requirements of the Resilience Information Portal while developing it. A classical development approach would have hindered this (consider e.g. [16], [17], [18]). For agile methods it is not typical to produce a functional specification because it is static (cf. [19], [20]). We have chosen to fix requirements in this form, nevertheless. The specification serves as a summary of results and provides cities with a starting point. It does not hinder an actual development of city portals that follows an agile method: we present requirements in form of so called user stories [21], which can serve as the starting point for an agile process.

The agile approach lead to an iterative, incremental and participatory, arguable even evolutionary implementation strategy (cf. [22]). The iterative nature mandated that features were not necessarily completed in one increment (step), and later changes were possible. Participatory means that we closely cooperated with the cities.

Our research design also took care of the idiosyncrasies of a large-scale project. On the one hand, the scope is enormous; working closely with seven cities and establishing contact to many municipal stakeholders is a great opportunity. On the other hand, regular physical meetings are not easy to set up, and coordination takes time. Moreover, such a project is typically sliced into tasks. Making a task-wise overall procedure compatible with an agile approach takes some discipline and consideration. In our example, social media services were integrated in the course of development.

\subsection{Related Work}

Much literature discusses emergency management and IS. [23] proposes nine premises, which we followed:

1) A system that is not used on daily-basis does not work correctly in case of actual emergency.

2) People responding to an emergency have no extra capacity for responding to issues unrelated to crises.

1. "Systems and software engineering - Life cycle processes - Requirements engineering", 2011
Table 1. Related Work

\begin{tabular}{|c|c|}
\hline Context & Requirements Described \\
\hline $\begin{array}{l}\text { Public he- } \\
\text { alth emer- } \\
\text { gency IS }\end{array}$ & $\begin{array}{l}\text { Surveillance system for emergency alert and response to } \\
\text { replace periodic manual reporting with online reporting } \\
\text { Database management system (DBMS) } \\
\text { Geographical information system (GIS) } \\
\text { Systems for remote sending, Analysis and prediction, } \\
\text { virtual reality, search and query, and decision support } \\
\text { Action system for resource planning and allocation }\end{array}$ \\
\hline $\begin{array}{l}\text { 5] Pre- } \\
\text { existing } \\
\text { teams col- } \\
\text { laboration }\end{array}$ & $\begin{array}{l}\text { Record widespread and detailed accounts of attributes } \\
\text { Track and display a wide variety of unsimplified data } \\
\text { Increase visibility of operational performance measures } \\
\text { Create a flexible system for simultaneous processing } \\
\text { Identify, and alert experts with ongoing problems } \\
\text { Support collaboration between crisis team and experts }\end{array}$ \\
\hline $\begin{array}{l}\text { [26] Information } \\
\text { sharing } \\
\text { in fire } \\
\text { brigades }\end{array}$ & $\begin{array}{l}\text { Information requirements for emergency response are } \\
\text { environmental conditions, information on response parti- } \\
\text { cipants, status of casualties, available resources } \\
\text { Prototype interface is designed to follow three levels of } \\
\text { action based on situation awareness theory: perception, } \\
\text { comprehension, and projection. Information should be } \\
\text { categorized in each level. }\end{array}$ \\
\hline $\begin{array}{l}27 \text { First } \\
\text { responders } \\
\text { emergency } \\
\text { response } \\
\text { system }\end{array}$ & $\begin{array}{l}\text { Web services allowing other applications data access } \\
\text { Multi-device, ensure location specific emergency plans } \\
\text { and evacuation notifications } \\
\text { Spatial data analysis } \\
\text { Voice XML, providing a bidirectional and seamless re- } \\
\text { sponse system that requires minimal human intervention }\end{array}$ \\
\hline $\begin{array}{l}\text { 28] Disaster } \\
\text { relief in } \\
\text { supply } \\
\text { chain ma- } \\
\text { nagement }\end{array}$ & $\begin{array}{l}\text { Geospatial applications that can provide useful data about } \\
\text { relief zones and reconstruction areas } \\
\text { Audio, video, or textual data, improving the technical } \\
\text { conversion between data nature and data capture } \\
\text { A social network component } \\
\text { Issues: dealing with incongruent data and data credibility. }\end{array}$ \\
\hline $\begin{array}{l}\text { [29] Knowledge } \\
\text { mana- } \\
\text { gement } \\
\text { system for } \\
\text { disaster } \\
\text { support }\end{array}$ & $\begin{array}{l}\text { Web-based, aiding emergency management of natural } \\
\text { disasters } \\
\text { Two core components: community portal and knowledge } \\
\text { repository for emergency managers } \\
\text { Additional functionality to support communication, coor- } \\
\text { dination and collaboration in crisis management }\end{array}$ \\
\hline
\end{tabular}

3) Storing past experiences (what happened before, during, and after the event) is crucial to improve responses.

4) Almost everything in a crisis is an exception to the norm.

5) The nature of crises requires people, authority, and relative resources to be together for a specific time period.

6) Predicting who is doing what during crises is almost impossible.

7) Keeping information up-to-date is important.

8) Preparing interoperability for information exchange is necessary as a crisis requires exchange between any kind of individuals, communities and institutions. Information overload should be considered.

9) Large crisis cannot be managed without coordination. However, we cannot identify responsibilities of involved people and organizations before the event (cf. point 6).

Regarding design requirements for an emergency response system, a number of elements can be retrieved from the literature, as shown in Table 1.

However, while much more work exists that in a few aspects connect to our activities, there is little sense in 
presenting a full overview here: Such an endeavour would lead to a literature study paper of its own. Therefore, we build on the above summarized works and cite further literature throughout this paper were appropriate. We hope that in the future the work on informational urbanism [30] can become a source of information on topics like ours.

It should be mentioned that also works exist in practice that are worth consideration. Again, there is a plethora of single-purpose systems, such as the host of geographical information systems that show some resilience-related data but do not have communication and collaboration as primary goal. A particularly noteworthy example is the UK's ResilienceDirect, an 'online private 'network' which enables civil protection practitioners to work together [...] during [...] an [...] emergency" [31]. A similar tool also exists in Norway, although the focus is on actual crisis response [32].

\section{Analysis and Design}

In the following, we explain how we approach the problem, describe how we came to the set of requirements for the portal, and elaborate on its design.

\subsection{Analysis}

The analysis contained two steps. First, we identified communication challenges of cities building urban resilience. This mainly was done by a pre-questionnaire to cities. We asked about (1) main communication activities to enhance urban resilience, (2) the most significant communication challenges in these activities, and (3) relevant stakeholders required for collaboration. Second, we derived design goals and principles to tackle challenges identified in the previous step. For this purpose, face-to-face interviews were conducted with in total 20 sets in six cities, ending up with 33 individuals involved. In these interviews, we asked ion detail, aiming to understand (1) how cities share information about risks and resilience with stakeholders, (2) how cities share knowledge and experience to develop a sense of community and learning partnerships around urban resilience, and (3) what future requirements cities and stakeholders have with respect to the possibility of developing a panEuropean communication platform.

The overview of communication challenges and design goals is shown in the Figure 2. Communication challenges varied from city by city.

First of all, cities needed to identify who they should contact and how communication between them can be done. We asked a number of questions: Should they work individually, or involve local communities or business groups? Are there digital divided people within these communities? Which kind of communication media (conventional paperbased, social networking services, official web page) should

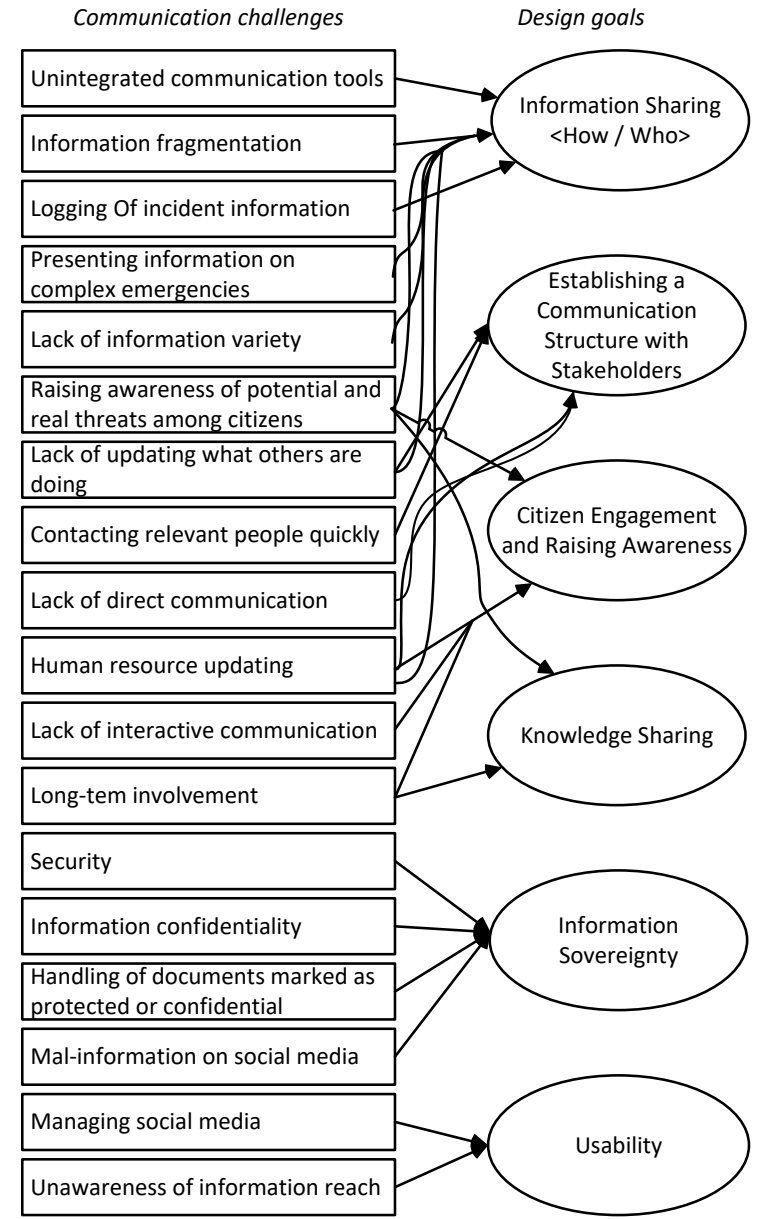

Figure 2. Communication challenges and design goals

cities set up for contact? How do these media enable cities to have dialogue with citizens and stakeholders?

The answers led to design goal (1) - information sharing. A communication structure between cities and stakeholders, which can be established through daily-basis operations, is essential in case of an emergency. In design goal (2) - establish a communication structure with stakeholders, visualization of live communication, considering who is contacting whom will help to enhance effective information sharing during an emergency. Several cities mentioned that visualization of resource capability and sharing an overview are crucial in establishing a communication structure with relevant stakeholders. However, none of interviewed cities has implemented an information portal for this purpose.

The design goal (3) - citizen engagement and raising awareness requires dialogue between citizens. The portal should employ functions to support interactive communication. Social media integration is a desired function by all cities. They started trying out social media several years ago; however, few best practices exist so far. Only involving citizens is not enough; Cities desire to see what other cities are doing in terms of urban resilience. Whereas the first design goal requires channel setting and target group 
identification within a city, design goal (4) - knowledge sharing describes disseminating best practices, concerns, and lesson learned on a wider scope, scaling from neighbours to other cities all over the world. Some cities already run a portal to share best practices on the national level, but no European and worldwide system exists.

While the first four design goals represent abstract notions of requirement, the two further goals should be considered as a technological foundation of the portal. Information quality and role-based authorization are demanded by design goal (5) - information sovereignty; including technologically disadvantaged people is part of the dissemination activities.

\subsection{Requirements Engineering}

Following the research process (cf. Section 2.2) and taking into account the design principles, we arrived at a set of requirements. Whereas it is not static - in fact, cannot be static due to the nature of the problem the portal seeks to mitigate -, the specification serves as a milestone in understanding how a portal should look like, what functionality it should provide, and which level of quality it needs to satisfy.

In the following, we summarize the key facts. Please note that the actual specification is much more detailed. We report here on a level of criteria, not on the level of user stories. The latter is required to actually implement a portal and for activities such as estimating development effort. The chosen level of detail facilitates an understanding of what kind of IT a city needs according to our findings.

The product definitions sets the creation of the Resilience Information Portal as the aim. This portal is meant to be a tool for communication and collaboration, and it should engage and ultimately empower citizens. Communication should be enabled within a city, between a city and its resilience-related stakeholders, and between a city and its citizens. Moreover, the portal should facilitate knowledge sharing as a long-term endeavour.

\subsection{Functional Requirements and Data}

A number of functions must be fulfilled by the portal ${ }^{2}$ :

1) The portal must be a publicly available Web-based information system with the basic requirements of such an application, such as page retrieval.

2) The portal must provide not only static pages but be ready for arbitrary dynamic content. This includes features such as newsfeeds, Weblogs, Wiki pages, and forums.

3) The portal must provide templates for often used data structures and their representation, such as a contact list.

4) The portal must allow existing dynamic content to be integrated. This should be possible by inlining existing Web sites and by integration XML-based data sources.

2. Despite repetitive in reading, we use must, should and could in every sentence referring to functionality to denote the respective priority
5) The portal must have use-friendly functions for updating content. A WYSIWYG editor should be provided.

6) It must be possible to represent complex information. This particularly addresses incident data.

7) The portal must provide users accounts, adequate authentication and authorization mechanisms, as well as a (adaptive) role management.

8) Users with adequate rights must be able to edit pages.

9) The role-concept must allow do design bi-directional communication flows. This for example is required to provide citizens with the possibility to give feedback.

10) The portal must provide a so called "emergency mode". This pre-defined home page should contain but the most relevant (live) data for a specific threat or emergency.

11) The portal must allow for the integration of social media.

12) A sufficient search functionality must be provided.

Several functions are desirable but not vitally needed:

1) The home page should be customizable for users.

2) The support of mobile devices should be guaranteed by a responsive design (cf. [33]).

3) A reminder function should be provided for editors. This follows the rationale that a lack of current information can be dangerous in case of crises, starting with as simple issues as not-updated telephone numbers.

4) Basic video conferencing should be enabled.

5) The portal should support multiple languages. In particular, it makes sense to provide the most important information also in languages spoken by groups not likely fully familiar with the local language.

6) Coupling with advanced information systems for crisis handling should be possible. This could for example apply to a workflow management system.

7) The portal should integrate with civil warning systems.

8) The portal should provide means for the city to monitor and scrutinize citizen's activity on social media. This could provide additional sources of information in crises.

To keep the portal adaptable for all cities, no further technological or paradigmatic recommendations are given. Architecture, programming language, platform, and frameworks can be freely chosen since these will not normally impede the realisation of the above sketched functionality.

Regarding data and data storage, no particular requirements are given but for those that derive from the functional scope. However, cities are advised to consider the topic of open data (cf. e.g. [34]) and to carefully design interfaces.

\subsection{Non-Functional Requirements}

There are several non-functional (quality) requirements to keep in mind. The portal most offer a sufficient level of security, keeping in mind the kind of data that is processed. Standard and guidelines exists in this regard; National laws need to be obeyed. Thus, we do not go into further detail. 
The portal must be user friendly and ergonomic to use. Besides adhering to usability best practices, it is recommended to follow pertinent standards, such as the EN ISO $9241^{3}$ series. Additionally, the portal must be inclusive for all citizens. Therefore, we strongly recommend following good practices of accessibility [35]. This e.g. allows seeingimpaired people to retrieve information.

While we made detailed suggestions regarding the graphical user interface of the exemplary portals in our project, no such recommendations are given in general. Besides realizing an ergonomic Web application, the only suggestion is to align the portal design with that of a municipal Web site - or to even directly integrate both seamlessly.

There are no specific requirements for the performance that go beyond what is nowadays expected for Web applications. For typical reaction times, the EN ISO 9241 standard series again is applicable. It particularly is advisable to use AJAX [36] to realize partial updates of pages. In case the portal must serve a high-number of requests in cases of crises, good scalability must be given.

The extensibility of the portal must be very good, both regarding content and functionality. Ideally, it should provide a plug-in concept. Likewise, a high level of maintainability is essential. The portal needs to have a good level of scalability to grow with an extended usage.

A typical level of robustness should be achieved. The portal must, however, not have a particularly high level of resilience - unless integrated with civilian warning systems and employed to warn the population in case of crises.

Compatibility and portability are important, but merely to the usual degree for Web application. There are no particular requirements regarding documentation since both frontend and backend of the portal should be intuitive to be used.

\subsection{Design}

As already suggested, design as the content of this section refers to system design, not to the set-up of the graphical user interface (GUI). An example for the implementation of the portal is given in Section 4 (as Figure 3 on p. 7). In this section, we focus on notable, generalizable design decisions.

We forwent proposing an architecture. The aim of creating a Web-based portal suggests a typical four-tier architecture, though. This comprises of a viewing layer, a presentation layer, the business logic, and a database abstraction. Besides that, we do not deem any particular backend design decisions with architectural impact recommendable. The maxim should be good integration with existing backend systems and, thereby, not increasing IT heterogeneity.

To support different groups of users, we suggest to implement the concept of entities. The basic idea is the

3. "Ergonomics of human-system interaction", especially parts 112 (2015-07-24), 125 (2016-05-13) and Part 161 (2014-06-06). following: Users register for the portal. Although the portal has public areas, customization and access to any restricted areas require logging in. If desired by a city, this might include an identity check to ensure that a registered user is eligible. Several users can be created in any entity. Depending on city preference, users purely registered may have the top level entity of the city. Alternatively, users could be only allowed to register if they are citizens (limiting e.g. e-government services) and thereby assume to be in a specific subentity of the city; the city is itself a entity.

Entities can be designed hierarchically. For example, a citizen might register as a volunteer. As such, he or she would receive extended information in case of a disaster if the entity created for volunteers has this permission. This may include the disclosure of otherwise confidential information, say whether elderly people with a home care system have reported to be home, or not. The volunteer entity is a subentity of the entity named citizen, i.e. whoever is a volunteer inherits rights applied to citizen.

Pages are tied to entities. This would restrict access to those who belong to the entities, making it easy to use the same portal for a variety of activities and for very different user groups. The portal is not only meant to city-citizen or city-stakeholder exchange, but for both. A hierarchical entity concept allows to create internal areas that are not accessible for the public. Moreover, it allows to form situation-dependent groups. For example, a page listing emergency resources could be created at a specific level of the hierarchy. Again, access might be tied to the portal being switched to emergency mode. One example for adaptability would be to limit the resource page to a specific entity fire fighter but in case of an emergency to open it also for voluntary fire fighters.

The Database layer can be classified in two parts: One layer for page content and security management, and one layer for user defined data sets. The latter may comprise addresses, flood levels, comments to pages or sections, and so on. This can be considered a metadata definition of different types of information that the user can define and allow other users to provide input for the database.

\section{Implementation and Testing}

Two particularities must be taken into account when considering the portal's implementation. First, our main focus on this paper is on conceptual aspects as the implementation of city portals in an ongoing endeavour. Second, generalizable advice can only be given to a certain degree. While we can present very thorough and very detailed work on analysis and requirements, the design of the portal also allows much freedom. This can be explained by the functionality we impose, which contrasts the small number of technological requirements that need to be followed. In consequence, both the implementation in the narrow sense (i.e. programming

Page 50 

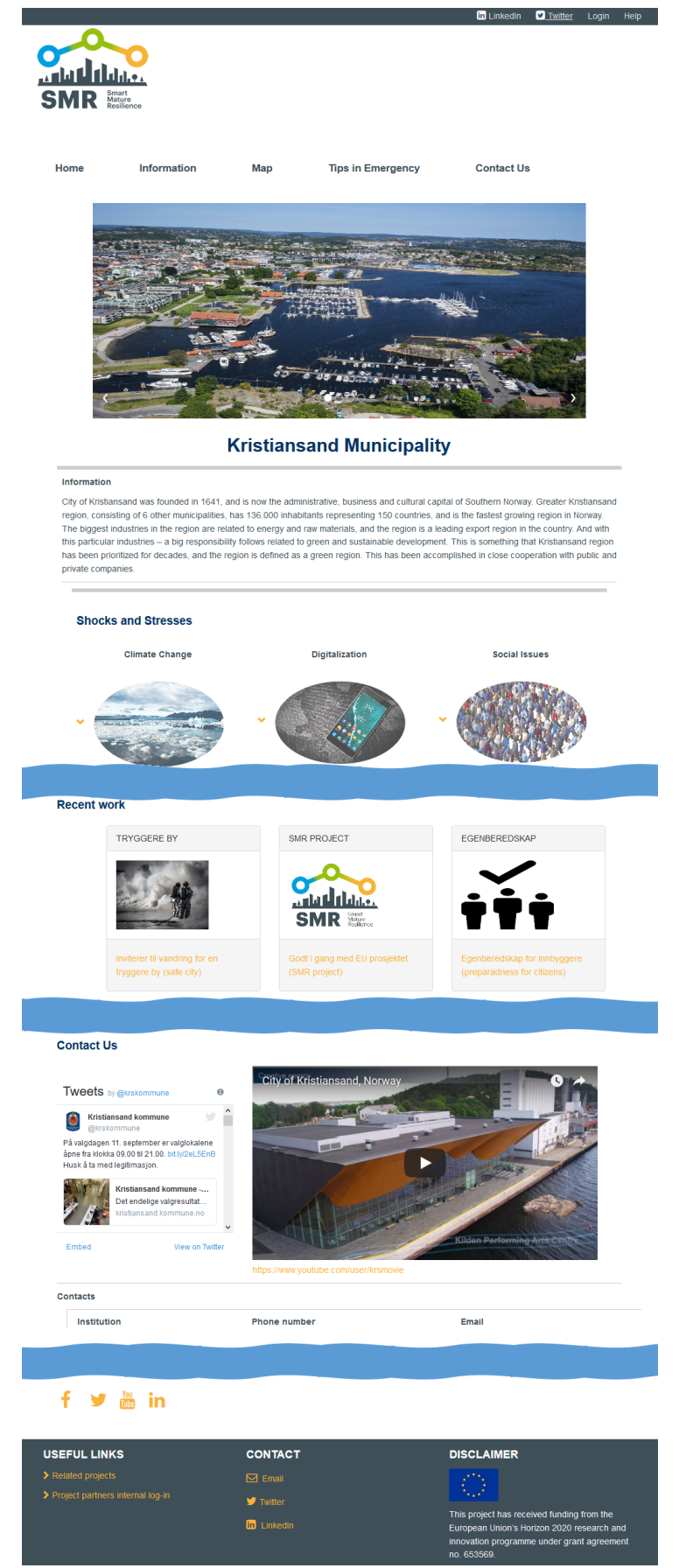

Figure 3. Exemplary (condensed) screenshot from a city portal

a city portal) and in the wide sense (i.e. setting it up in a city and linking it up with processes) are highly cityspecific. Presenting some insights, however, should help in getting a more concrete picture of what the - admittedly due to their nature quite abstract - requirements mean. An example of a city portal created with the portal toolbox is shown in Figure 3 It shows a typical entry page of a portal that summarizes different content and features.

Implementing the portals for the participating cities is a two-step process. For three cities, we have implemented exemplary portals based on their particular requirements and content. We took advantage of the Resilience Information Portal being provided in the project as a toolbox. These cities now evaluate and use these portals to try out functionality.

The second step is the creation of seven city portals. It is intended that the three cities with portals from the first step will recreate the portals without our technological aid. We will have only the role of an advisor, ensuring that portals aligned with the IT and communication strategies of a city. We deem this vital to ensure long-term usage as portals with be realized in a way in that they integrate with existing IT.

While it might be seen as a waste of resources to reimplement the portals of three cities, it is not. It goes along with our incremental and iterative process. Moreover, it contributes to the discovery of what cities really need, as it would be futile to impose technology onto them that will become "yet another information system" that is not accepted. The three portals implemented by us allow cities to learn what works for them - and in particular, what not.

The technical testing of a Resilience Information portal is relatively simple. It follows techniques typical for the testing of IS (cf. e.g. [37, Cha. 2]), in particular for the testing of Web-based systems (cf. e.g. [38]). Evaluating the merits of a portal is much more complex. The same applies for assessing whether the portal is well-integrated with the processes of a city. Eventually, it needs to be determined if a city's portal truly helps this city to become more resilience.

Testing scenarios can be used both to derive test cases for the technical activities and for evaluation. For this purpose, we conducted an exercise with our partner cities in which they had to develop scenarios. City council members and stakeholders formed groups and discussed two scenarios proposed by us. They could either extend the scenarios or develop new ones. Each city should come up with one scenario that captured a shock and one that captured a stress.

In the second step, the exercise participants discussed which portal functionality is required to mitigate the consequences of the respective shock and stress. We asked them to do this in a way providing several levels, i.e. to describe which functionality is required for any city and which portal features would be increasingly hard to implement but also leverage better and better urban resilience. As with all our activities, the exercise served a twofold purpose: aiding our understanding, helping us in proposing a suitable Resilience Information Portal, and stimulating discussion in a and between cities to help them build their resilience strategy.

The detailed results from the exercise go beyond the scope of this paper; thus, we provide a summary. In general, cities acknowledge that scenario creation is laborious but would be quite helpful for reflecting on the situation in a city. Moreover, scenarios might be re-used for other purposes such as emergency stakeholder training. In alignment with our expectation, the core functionality needed for a portal 
is similar for shocks and for stresses, but it becomes more differentiated depending on the level of resilience sought. In addition to this, it can be ascertained that the functionality for different kinds of shocks is rather similar, despite very different natures of the shocks. While a flooding and a tunnel fire require very different measurements in terms of crisis mitigation, the requirements towards IT, and in particular towards communication and collaboration are very similar. We made the same observation for stresses, also it could be argued that the variety of features might be a bit higher since different stresses involve different stakeholders. Compare e.g. refugee movements with diminishing public health while a single portal to keep the population informed makes much sense, differences in details are easily imaginable.

\section{Discussion}

We first suggest which lessons can be learned. Then, we name questions that remain open before leading to the limitations. Eventually, we discuss future work.

\subsection{Lessons Learned}

The iterative, incremental nature of our process, and the close and continuous involvement of the partner cities allow us to derive general findings from our experiences.

First of all, we can ascertain that the general process chosen for the creation of the Resilience Information Portal is feasible. Combining several research methods in a practical settings was not guaranteed to succeed. However, we deem the longevity of the approach to be important. Moreover, it was accepted by the project partners that we would not come up with a quick solution. Creating a simple portal from bootstrapped requirements would have been possible in mere weeks; whether such a portal would have served the cities must be doubted. In fact, we even deem it dangerous to conclude that with a rough knowledge of a domain and with technological proficiency a sustainable solution can be proposed. Therefore, it is worth sharing that an agile development process with a participatory character works well. We would even recommend our evolutionary approach, admitting that the developers not fully know the destination when they start out with the development journey.

Connected to the first observation is a second one: trust is vital in a project like ours. Only through the trustful relationship to cities we gained the necessary insights in their work; only because the cities had trust in our work they evaluated the proposals we made to them and helped us with the ongoing portal development. Trust did not only play a role within the confines of the project, though. Cities ensured that stakeholders were involved and put effort in establishing a good relationship between all participating parties. Resilience by itself can be ascertained to be a topic that heavily relies on trust [39], particularly if citizens are seen as the foundation. Therefore, we deem trust a precondition for any endeavours similar to those we describe.

A third experience concerns the connectedness within a city. A portal is not independent entity in the resilience strategy. Rather, a city needs to consider its aims and integrate a Resilience Information Portal in this strategy. Engaging citizens can be well supported using a portal, e.g. giving them a platform to self-organize neighbourhood help. However, not all citizens can be reached online, or at least not in all cases. Thus, online activities need to be linked with offline work. We found this also to be particularly true for the integration of social media. It may be futile to believe that social media must be used to reach more citizens: Just the same citizens like before may see notifications, but now via more than one channel. Finding a mixed-channel strategy that seeks to "leave no one behind" is what a city needs.

We ascertain that not only related activities need to be coordinated, but that a city must have an overall strategy towards resilience. This strategy must interact with that of other areas. In particular, we deem important

- the IT strategy (to set up a portal, and to link it with data sources and resilience-related information systems),

- the communication strategy (because resilience is achieved through improved communication on many levels), and

- the collaboration efforts (since resilience is also the synergy of activities).

\subsection{Open Questions}

While we have learned much about the requirements of cities, we can neither draw a full agenda of IT support for resilience nor exhaustively suggest how a city's communication strategy should look like. Rather, through our work we have answered many questions but raised new ones.

First, it is not fully discovered how legal requirements, public pressure, the needs of municipalities, and insights from practice can be combined with scientific results. Their combination could yield profoundly better IT support for resilience, but how to achieve this alignment is not yet clear.

Second, and going into a similar direction, the links between a city's IT strategy, its communication strategy, its effort in collaborating with stakeholders, and the engagement of its citizens need to be uncovered. If we understand, how these topics integrate or even interconnect, more specific solutions will be provisionable.

Third, how a portal can be created technologically is well understood. However, how to make a portal actually serve the population must be further scrutinized. Despite our work providing some insights, longitudinal studies are needed, which cover experimental and explorative, qualitative, and eventually quantitative tasks. In particular, open questions remain with regard to the populations' motivation in using a portal, to their willingness to contribute to resilience, and 
to the effectiveness of empowering them. In general, it will need to be described how a portal such as ours can be tested, and what metrics can be used to assess its effectiveness (cf. also [2] for the question how to measure resilience).

Fourth, there are also technological challenges that go much beyond the development of Web technology. An allencompassing Resilience Information Portal should include many data sources. It is unclear how a semantic integration of data is achievable on such a portal. Imagine e.g. that it would integrate systems that provide weather data and infrastructure measurements, and combine such data with reports from emergency agencies and even current social media events. It could in a big data fashion possibly warn of imminent, yet not obvious threats. While for example map mashups exist [40], how to effectively leverage such possibilities for a portal is a task of future research.

\subsection{Limitations}

First, there are some boundaries to the work on an IT artefact to support city resilience in general. Second, the work presented in this paper has limitations.

A general boundary of the work in the project as a whole lies in the research method. We can propose notable findings and even evaluate these findings with the project partners and also with external cities, but the work underlies the typical limitations of case-study based work. It is likely that we learn enough from our seven partner cities to propose methods and artefacts that are general enough to also serve in other circumstances, but there is no guarantee for this.

Specifically for the work on the portal, we face a boundary imposed by the complexity of the background in the cities. The portal should facilitate resilience but it needs to be tailored to the (typically heterogeneous IT infrastructure) and be aligned with the communication processes. Moreover, it must be accepted by city users and stakeholders. Eventually, it needs to be used by the citizens. On top of all of that, the set up, implementation, and maintenance of the portal needs to be reflected not only in the resilience strategy but again in the IT and communication strategies including all of their dependencies. Whereas best practices for solving these challenges exist, and while we believe we have taken mindful decisions to cater for a successful adoption, this setting poses a limitation in itself. At least for some cities delays in the adoption can be expected.

The work presented in this paper "inherits" the general limitations. Additionally, it provides results that will need to be proven by year-long practical usage. We deem our work very promising and we have received much positive feedback as well as ideas for improvement from our city partners. However, whether all our suggestion work well in the long run will only become evident in a few years.

Neither the general boundaries not the specific limitations impede the value of our work, though. In fact, in conjunction with the open questions discussed above they provide the foundation for our future activities.

\subsection{Future Work}

Our journey towards more resilient cities is far from being over. Tasks for future work can be derived from the open questions and also from the limitations.

First, future work follows the software engineering steps not covered with so much detail in this paper. In particular, the implementation of the portal in a number of cities is a future task. This will allow us to extensively test and evaluate the portal. Moreover, it will pave the way towards better support for cities, e.g. in form of guidelines. Although this is not in our own scope, a consultancy business model might be a result from this process.

Second, we seek to contribute to the theory by providing a better understanding of the interlinkage of IT, communication, and collaboration. We will back up this work again on empirical data, both from the existing work with the cities and from the above mentioned evaluation of the portal.

Third, we will assess a broadening of our scope beyond the research project. The aim is to find new fields that ought to be conquered, but where we profit from having the existing results regarding urban resilience. We hope that we can involve our partner cities in this work.

Fourth, we will propose the functional specification of the portal to become a standard. This will be the ultimate technological generalization of our work. It should aid cities in adopting a portal, and also provide them with a rationale when deciding for implementing it.

\section{Conclusion}

In this paper we have presented work on a Web-based information system. The Resilience Information Portal seeks to support communication and collaboration, helping cities in becoming more resilient. Thereby, it should improve the link between a city and its resilience-related stakeholders. Even more importantly, we deem it an appropriate tool to engage citizens and to empower them in becoming a vital part in the resilience endeavours of their city. The portal has been created in close collaboration with seven cities.

While the conceptualization of the portal is finished, the implementation in the partner cities is ongoing. Moreover, not only the portal but all tools originating from our project will be proposed to selected cities that will serve as early adopters. We seek additional feedback and want to provide more implementation advice as well as usage best-practices. Our own work will not only go into this practical direction but we will also contribute to theory. Moreover, we will propose the functional specification as a whole to become a standard. We hope this to make it easier for cities to embed a portal in their resilience and IT strategies. 


\section{Acknowledgements}

This work was supported by the European Union's Horizon 2020 Research and Innovation program [grant agreement number 653569]. We would like to thank the cities for their cooperation, and ICLEI for their effort in implementing the portal in the cities. Please note that Figure 1 was reproduced from project deliverables that have the same authors as this paper. We, thus, do not cite these.

\section{References}

[1] "100 resilient cities," 2017. [Online]. Available: http: //www.100resilientcities.org/

[2] J. Hernantes, L. Labaka, M. Turoff, S. R. Hiltz, and V. A. Bañuls, "Moving forward to disaster resilience: Perspectives on increasing resilience for future disasters," TFSC, vol. 121, pp. $1-6,2017$.

[3] C. S. Holling, "Resilience and stability of ecological systems," Annu. Rev. Ecol. Syst., vol. 4, no. 1, pp. 1-23, 1973.

[4] A. Tatnall, Web portals: the new gateways to Internet information and services. IGI Global, 2005.

[5] S. V. Zykov, "Integrating enterprise software applications with web portal technology," arXiv preprint cs/0607127, 2006.

[6] J. Davies, Y. Sure, H. Lausen, Y. Ding, M. Stollberg, D. Fensel, R. Lara Hernández, and S.-K. Han, "Semantic web portals: state-of-the-art survey," Journal of knowledge Management, vol. 9, no. 5, pp. 40-49, 2005.

[7] W. W. Royce, "The development of large software systems," in Proc. IEEE WESCON 1970. IEEE CS, 1970, pp. 328-338.

[8] B. W. Boehm, "Software engineering," IEEE Transactions on Computers, vol. 25, no. 12, pp. 1226-1241, 1976.

[9] "World's population increasingly urban with more than half living in urban areas," 2014. [Online]. Available: http://www.un.org/en/development/desa/news/population/ world-urbanization-prospects-2014.html

[10] "Urban europe - statistics on cities, towns and suburbs - patterns of urban and city developments," 2017. [Online]. Available: http://http://ec.europa.eu/eurostat/ statistics-explained/index.php/Urban_Europe_\%E2\%80\% 94_statistics_on_cities,_towns_and_suburbs_\%E2\%80\%94_ patterns_of_urban_and_city_developments

[11] R. Gimenez, L. Labaka, and J. Hernantes, "A maturity model for the involvement of stakeholders in the city resilience building process," TFSC, vol. 121, pp. 7 - 16, 2017.

[12] N. Serrano, J. Hernantes, T. A. Majchrzak, and M. Sakurai, "Resilience information portal," in Proc. 14th ISCRAM. ISCRAM Association, 2017.

[13] C. Grimes, M. Sakurai, V. Latinos, and T. A. Majchrzak, "Co-creating communication approaches for resilient cities in europe: the case of the EU project SMR," in Proc. 14th ISCRAM. ISCRAM Association, 2017.

[14] I. Sommerville, Software Engineering, 9th ed. Pearson, 2011.

[15] H. Balzert, Lehrbuch der Softwaretechnik. Spektrum Akademischer Verlag, 2009.

[16] A. Cockburn, Agile Software Development: The Cooperative Game, 2nd ed. Addison-Wesley, 2006.

[17] K. Schwaber, Agile Project Management with Scrum. Microsoft Press, 2004.

[18] R. Turner and B. W. Boehm, "People factors in software management: Lessons from comparing agile and plan-driven methods," CrossTalk Magazine, pp. 4-8, 2003.
[19] T. Heap, "An agile functional specification," 2017. [Online]. Available: http://www.its-all-design.com/ an-agile-functional-specification/

[20] K. Beck, Extreme Programming Explained: Embrace Change. Addison-Wesley, 1999.

[21] M. Cohn, User Stories Applied. Addison-Wesley, 2004.

[22] S. Dyck and T. A. Majchrzak, "Identifying Common Characteristics in Fundamental, Integrated, and Agile Software Development Methodologies," in Proc. 45th HICSS. IEEE CS, 2012, pp. 5299-5308.

[23] M. Turoff, M. Chumer, B. Van de Walle, and X. Yao, "The design of a dynamic emergency response management information system (DERMIS)," JITTA, vol. 5, no. 4, 2004.

[24] Y. Xue and H. Liang, "Is-driven process reengineering: China's public health emergency response to the SARS crisis," JITTA, vol. 6, no. 3, 2004.

[25] E. H. McKinney, "Supporting pre-existing teams in crisis with it: a preliminary organizational-team collaboration framework," JITTA, vol. 9, no. 3, 2008.

[26] L. Yang, R. Prasanna, and M. King, "On-site information systems design for emergency first responders," JITTA, vol. 10, no. $1,2009$.

[27] M. A. Thomas, F. K. Andoh-Baidoo, R. Redmond, and V. Y. Yoon, "Moving beyond traditional emergency response notification with VoiceXML," JITTA, vol. 10, no. 1, 2009.

[28] J. M. Day, S. A. Melnyk, P. D. Larson, E. W. Davis, and D. C. Whybark, "Humanitarian and disaster relief supply chains: a matter of life and death," Journal of Supply Chain Management, vol. 48, no. 2, pp. 21-36, 2012.

[29] M. Dorasamy, M. Raman, and M. Kaliannan, "Integrated community emergency management and awareness system: A knowledge management system for disaster support," TFSC, vol. 121, pp. 139 - 167, 2017.

[30] J. Barth, K. Fietkiewicz, J. Gremm, S. Hartmann, A. Ilhan, A. Mainka, C. Meschede, and W. Stock, "Informational urbanism. a conceptual framework of smart cities," in Proc. 50th HICSS, 2017.

[31] "ResilienceDirect," 2017. [Online]. Available: https://www. gov.uk/guidance/resilient-communications \\#resiliencedirect

[32] "DSB-CIM Grunnkurs," 2017. [Online]. Available: https:// www.dsb.no/kurs-og-konferanser/nusb/dsb-cim-grunnkurs3/

[33] M. Nebeling and M. C. Norrie, "Responsive design and development: Methods, technologies and current issues," in Proc. ICWE. Springer, 2013, pp. 510-513.

[34] M. Janssen, Y. Charalabidis, and A. Zuiderwijk, "Benefits, adoption barriers and myths of open data and open government," Inf. Sys. Mngmt, vol. 29, no. 4, pp. 258-268, 2012.

[35] S. L. Henry and L. McGee, "Accessibility," 2017. [Online]. Available: https://www.w3.org/standards/ webdesign/accessibility

[36] J. J. Garrett et al., "Ajax: A new approach to web applications," 2005. [Online]. Available: http://adaptivepath. org/ideas/ajax-new-approach-web-applications/

[37] T. A. Majchrzak, Improving Software Testing: Technical and Organizational Developments. Springer, 2012.

[38] N. Mansour and M. Houri, "Testing web applications," Inf Softw Technol, vol. 48, no. 1, pp. 31-42, 2006.

[39] D. P. Aldrich and M. A. Meyer, "Social capital and community resilience," American Behavioral Scientist, vol. 59, no. 2, pp. 254-269, 2015.

[40] S. B. Liu and L. Palen, "The new cartographers: Crisis map mashups and the emergence of neogeographic practice," Cartogr Geogr Inf Sci, vol. 37, no. 1, pp. 69-90, 2010. 